"I like being a teacher": Career satisfaction, the work environment and work engagement

\begin{abstract}
Purpose: This research compared the efficacy of two theoretical frameworks in regard to explaining the work engagement of 312 Queensland teachers from non government schools. The first theoretical model is the Job Demands Resources (JD-R) theory which suggests that work engagement will be evident if people report an abundance of resources in their work environment. The second perspective is Self-Determination Theory (SDT) which suggests that work engagement will be evident if people are able to satisfy their personal psychological needs within the work environment.
\end{abstract}

Design/methodology/approach: The current research collected data from the same participants on two occasions with a six month interval. Hierarchical multiple regression analyses were conducted to test the research hypotheses both cross-sectionally and longitudinally.

Findings: It was found that the SDT provided more compelling explanation for work engagement, in that career satisfaction (rather than job satisfaction) was a robust predictor of work engagement, although some evidence was also found for a contribution of the psychosocial work environment (supporting the JD-R) in teachers' work engagement or burnout. It was concluded that these two theoretical perspectives are compatible.

Practical implications: It is recommended that future studies of work engagement include some measurement of people's satisfaction that career they have chosen fulfils their personal aspirations 
"I like being a teacher": Career satisfaction, the work environment and work engagement

Social implications: The theories of SDT (work engagement as a fulfilment of psychological needs) and JD-R (work engagement as a balance of job demands and resources), while coming from different directions appear to be compatible, with each perspective enriching the other and affording administrators a more complete understanding of dynamics affecting the psychological health of teaching staff.

Originality/value: Previous work involving the JD-R and work engagement has focused on the immediate psycho-social environment of the work place. The current research finds that career satisfaction predicts all dimensions of work engagement in cross-sectional analysis and over time. This supports insights from SDT and suggests that a more complete understanding of the dynamics of work engagement must include people's opportunity to redress psychological needs within the workplace.

Keywords: Work Engagement, Teachers, career satisfaction. Self-Determination Theory, Job Demands and Resources Theory.

Paper type Research paper 
"I like being a teacher": Career satisfaction, the work environment and work engagement

Introduction

Previous research has identified work engagement and work burnout as important markers of workers' mental well-being, and has linked both constructs to the psycho-social work environment experienced by employees (e.g., Bakker and Demerouti, 2007, Maslach et al., 2001, Schaufeli, 2004). According to the International Labour Organisation (ILO, 2000) not only does burnout severely compromise the mental health of workers but it is associated with increased costs to industry through sick days, increased staff turnover, and reduction in productivity. Teachers' burnout can be especially devastating because of the amount of emotional labour involved and the loss of a sense of commitment (see, Fink, 2003). Consequently it is an imperative that school administrators become fully cognisant of the adverse conditions that cause burnout among teachers and promote what is thought to be its positive counterpart, work engagement (e.g., Bakker and Demerouti, 2007, Maslach et al., 2001, Schaufeli and Bakker, 2003). Work engagement is generally recognised as a condition of optimal worker well-being that is associated with greater worker contentment, input and productivity. It is therefore in the interests of school administrators to reduce teacher employee burnout and to promote environments that contribute to the proliferation of engagement (Schaufeli, 2004). Work burnout

Burnout is most often described as a syndrome, with exhaustion (a feeling of being overwhelmed) and cynicism (depersonalisation) being the most frequently described attributes (Maslach et al., 1996). Cynicism was called disengagement by Demerouti and colleagues (2002) who suggested that it is a psychological distancing mechanism that has cognitive, physical and 
"I like being a teacher": Career satisfaction, the work environment and work engagement

emotional effects. Sonnentag and Bayer (2005, p. 393) suggested that disengagement can occur as an involuntary response when people feel that it is not possible to achieve voluntary restorative psychological detachment (“switching off”) from the demands of work.

\section{Work engagement}

Work engagement represents a juxtaposition of two important traditions of organisational investigation. The first, as previously mentioned, derives engagement from a tradition of burnout research seeing it as an antipodal construct to burnout with the same predictors (Maslach et al., 2001). An alternative view perceives work engagement as a state representing fulfilment of basic psychological needs (May et al., 2004, Ryan and Deci, 2000, Ryan and Deci, 2001). Maslach and Leiter (1997, p. 24) described burnout as "the erosion of engagement", observing that people are not burned out at the commencement of their jobs, but burnout develops as “energy turns into exhaustion, involvement turns into cynicism and efficacy becomes inefficacy".

This research will draw from two theoretical accounts for work engagement, these are the Job-Demands-Resources model (JD-R, Demerouti et al., 2001) and the Self-Determination Theory (SDT, Ryan and Deci, 2000, Ryan and Deci, 2001).The JD-R has traditionally had wider application than the SDT because it is applied to work burnout as well as work engagement. However the current research will apply perspectives from these two traditions to both work engagement and burnout to explore their explanatory relevance. We will demonstrate that a combination of these two theoretical traditions provides for a more comprehensive understanding of important markers for organisational success than has been possible in previously conducted research.

Explanations for the development of work burnout and engagement 
"I like being a teacher": Career satisfaction, the work environment and work engagement

\section{The Job Demands-Resources model}

The Job Demands-Resources model (Demerouti et al., 2001, Bakker and Demerouti, 2007) posits that work engagement can be predicted by balance (and burnout by imbalance) of demands and resources within the work environment. An example of demands within the work environment of teachers is provided by educational reforms which involve considerable extra paperwork and other tasks, thereby increasing teachers' workloads without factoring time for their completion into the school day (see, Easthope and Easthope, 2000, Timms et al., 2007, Williamson and Myhill, 2008). In his documentation of events in a Canadian high school Fink (2003) referred to this phenomenon noting that teachers who had previously been happy to undertake honorary and voluntary duties (such as supervising weekend sport), were now reluctant to do so. Fink (2003) observed that while teachers remained committed to their students (in terms of general education), a sense of professional identity was severely eroded and people found themselves in the position of having to balance the needs of their families against their desire to progress their careers. For many professionals in the modern world, this balance can be tenuous (Timms et al., 2008, O'Driscoll et al., 2010) and threatened by increasing workloads (Fink, 2003, Gardner and Williamson, 2006).

According to Bakker and Demerouti (2007) resources include those factors of the work environment that facilitate and enrich people's working lives. The theoretical perspective that an abundance of resources is associated with work engagement is endorsed in JD-R literature, with one of the most effective effective resources being support provided by supervisors and colleagues (e.g., Brough and Pears, 2004, Maslach and Leiter, 2008, Timms et al., 2012). According to Howard and Johnson (2004) the support of administrators is instrumental in building resilience in teachers in the face of challenges posed by problematic student behaviour. 
"I like being a teacher": Career satisfaction, the work environment and work engagement

An important part of that support (and trust building) in regard to the relationship between employees and management is the consistent practice of fair procedure within the work environment (Maslach and Leiter, 2008, Kim and Mauborgne, 2005). Yet another important resource often reported by engaged workers is a sense of having an effective balance between their work and non-work lives (e.g., Brough et al., 2009a). According to Grzywacz and Marks (2000) having a positive interface between people's work and family lives enriches both domains, whereas a negative interface undermines people's capacities in both domains (see also, Greenhaus and Powell, 2006).

Interestingly, Dollard and Bakker (2010) recently reframed the JD-R in a new model which incorporated organisation's psychosocial safety climate (PSC). Dollard and Bakker's model placed demands and resources as mediators of the PSC which was determined by management actions. This perhaps demonstrates some convergence of the two perspectives as the description of the PSC has parallels with May et al.'s (2004) concept of psychological safety. Similar to May et al. Dollard and Bakker also demonstrated that the PSC significantly predicted employee levels of both work engagement and burnout. Therefore it would seem that after quite some time JD-R theorists are beginning to recognize that a sense of psychological safety is also a contributor to people's engagement with their work. Psychological safety is a central component of the SDT (May et al., 2004) where people feel secure that they are in a dependable environment which allows them to pursue organizational goals while fulfilling their psychological needs. Kim and Mauborgne $(1998,2005)$ called this emotional and intellectual recognition and associated it with employees who apply ingenuity, persistence and creativity within their work. They advocated an intentional strategic cultivation of such a workplace climate by organisational management as a tool for achieving outstanding productivity gains. 
"I like being a teacher": Career satisfaction, the work environment and work engagement

\section{Self Determination Theory (SDT)}

The second explanation of work engagement comes from the SDT (Ryan and Deci, 2001, Ryan and Deci, 2000) where eudaimonic well-being (a sense of having achieved one's potential and consequently of being fulfilled) is embraced as an important propeller of human motivation at work (see also, Rothbard, 2001). According to the SDT, environmental conditions that foster people's innate psychological needs and tendencies towards personal growth enable optimum well-being. Ryan and Deci (2000) identified three inherent psychological needs (autonomy, relatedness and competence) which they saw as essential to personal growth and well-being. This has resonance with Gill's (1999) suggestion that the work environment can provide the opportunity for redress of basic psychological drives to achieve one's potential, simply because people spend a large proportion of their time at work. According to the SDT, people's work provides them with the opportunity to demonstrate their competence, develop working relationships with others and to decide how they will proceed with challenges. May et al. (2004) suggested that satisfaction of psychological needs at work not only drives intrinsic motivation (essential for the most productive work), but is also essential to the development of engagement with work.

Saks (2006) associated work engagement with deep levels of job satisfaction and asserted that its dimensions were simultaneously cognitive, emotional and behavioural. According to Saks, people who are engaged are realising the fulfilment of their aspirations within their work environment. This has resonance with previous research conducted by Rousseau (1995) which suggested that people bring expectations to their employment that constitute their psychological contract. Fulfilment of expectations and aspirations of individual potential therefore constitutes an important source of immense satisfaction and engagement in work. 
"I like being a teacher": Career satisfaction, the work environment and work engagement

\section{Work engagement from the SDT and JDR perspectives}

Descriptions from the two perspectives on work engagement share considerable overlap. Schaufeli and Bakkers' (2003) measure of work engagement provides a good starting point to illustrate this commonality. According to Schaufeli and Bakker there are three dimensions to work engagement: vigour, dedication and absorption. All of these dimensions have been described (but not necessarily named) within the SDT literature. The first dimension of vigour is described as keenness to invest effort because the individual is resilient and has reserves of energy. Schaufeli and Bakker perceive vigorous workers as those who would persist in the face of difficulties. Within the SDT literature, Ryan and colleagues (2008) described what they called vitality as a product of a life characterised by meaning and purpose. This suggests that having a meaningful and fulfilling job is energising. Ryan and Deci (2001, p. 146 ) also described a feeling of being "intensely alive and authentic" through engagement with work. These SDT descriptions, therefore, have a similar texture but diverge slightly from Schaufeli and Bakker's description of vigour.

Schaufeli and Bakker (2003) described engagement's second dimension of dedication as a reflection of meaning, sense of fulfilment and pride in one's work. The dedication dimension of work engagement bears a close resemblance to descriptions of eudaimonic well-being expressed within the SDT literature (Ryan and Deci, 2001, Saks, 2006). In view of this obvious convergence it is curious that most research investigates the antecedents of dedication primarily with psycho-social workplace variables such as work demands and work resources (e.g., Demerouti et al., 2001, Bakker et al., 2007, Schaufeli et al., 2008). In doing so the JD-R bypasses employees' anticipation of professional satisfaction which has been demonstrated to be an important antecedent of dedication within both the psychological contract literature (e.g., 
"I like being a teacher": Career satisfaction, the work environment and work engagement

Miller, 2001, Rousseau, 1995) and the SDT literature (May et al., 2004, Ryan and Deci, 2001, Saks, 2006), as well as literature on education (e.g., Friedman, 2000, Hargreaves and Fink, 2004).

Schaufeli and Bakker's (2003, p. 5) third engagement dimension is absorption, where people are "happily engrossed in their work" to the extent that they tend not to notice the passage of time. This has parallels with Rothbard's (2001) twin constructs of attention and absorption. According to Rothbard, workers exhibiting these characteristics are cognitively available to apply their best thinking to a task and are not distracted by other events around them. Also related to absorption is Csikszentmihalyi's (1990) flow theory, which according to Schaufeli and Bakker (2003) has some overlap with work engagement in that it describes optimal work experience (see also, Beard and Hoy, 2010). According to Schaufeli et al. (2008) absorption has a more enduring and persistent nature than flow, which refers to short-term peak experiences.

Where the SDT and JD-R positions diverge is at the starting place or 'headwaters' for motivation at work. According to JD-R theory (Bakker and Demerouti, 2007, p. 313) an abundance of resources is motivating, and leads to "high work engagement, low cynicism and excellent performance”. However the SDT (May et al., 2004; Ryan and Deci, 2001) suggests that psychological needs are the source of motivation. Ryan and Deci (2000, p. 70) described how intrinsic motivation is "an evolved propensity" and that conditions conducive to its expression will allow for its fulfilment. We suggest, therefore, that people's choice of career will usually reflect these intrinsic psychological needs and that individuals' expressed career satisfaction may provide a measure of this process.

Self-Determination perspectives can also be applied to work burnout. Friedman (2000, p. 601 ), suggested that teachers who are unable to fulfil their expectations of a fulfilling and 
"I like being a teacher": Career satisfaction, the work environment and work engagement

satisfying career of contributing to the psychological and intellectual growth of students, will inevitably experience a sense of "unaccomplishment", which directly undermines their sense of professional self-efficacy (see also, Bandura, 1969, Rosenstock et al., 1988). Teaching as a career is highly complex; it involves multiple relationships, challenges and demands that test one's personal resources, ability to cope and stamina. According to Friedman, the reality shock associated with unaccomplishment constitutes an existential crisis where teachers' expectations of themselves must necessarily be lowered to accommodate new realities. Friedman suggested that if psychological accommodation does not occur, workers (teachers) will inevitably develop burnout.

This account therefore attributes burnout to a sense of personal failure to fulfil aspirations and differs sharply from the explanations that burnout is primarily caused by factors residing within the psycho-social work environment (Bakker and Demerouti, 2007; Maslach and Leiter, 2008). While there is abundant evidence to suggest the psycho-social environmental accounts are indeed linked with burnout (Maslach et al., 2001), it is possible that Friedman's thesis may provide some insight into the development of work engagement that is consistent with May et al.'s (2004) perspective. For example, successful negotiation of the existential crisis that is central to Friedman's model could provide a sense of professional self-efficacy and career satisfaction that was fulfilling and would be consistent with work engagement.

Satisfaction with work

Shaver and Lacey's (2003) research distinguished between two types of work-related satisfaction: (1) job satisfaction defined by a worker's immediate work environment and their employer (e.g., "I am happy with my current work environment") and (2) career satisfaction defined by a worker's choice of career and how the experience of work had justified that choice 
"I like being a teacher": Career satisfaction, the work environment and work engagement

(e.g., "overall I am satisfied with my choice of career”). Shaver and Lacey's study of professional nurses found that older nurses tended to have lower levels of career satisfaction than did younger nurses, but the two groups had comparable levels of job satisfaction. It is observed that career satisfaction covers a sense of psychological need fulfilment, we have used this variable to test respondents' sense of self-determination in relation to work engagement in the current research.

\section{Aim and hypotheses}

This research proposes that career satisfaction provides an assessment of the extent of fulfilment of innate psychological needs (Ryan and Deci, 2000), generates psychological meaning in people's work (May et al., 2004), and is significantly related to work engagement. Therefore it is proposed that strong relationships between career satisfaction and work engagement will be consistent with the SDT (Ryan and Deci) perspective. It is also predicted that career satisfaction (because of its relationship to career choice and people's expectations of their job) will have a more enduring (over-time) association with work engagement, compared to specific psycho-social characteristics of the work environment more traditionally associated with the JD-R (Demerouti et al., 2001). Additionally, because work engagement is widely considered to be either the positive antipode of work burnout (Maslach and Leiter, 2008) or a construct that consistently has a negative relationship with work burnout (Schaufeli et al., 2008), it is expected that career satisfaction will also demonstrate a negative relationship with work burnout:

Hypothesis 1a: Career satisfaction will be significantly and positively associated with each of the three dimensions of work engagement (vigour, dedication and absorption) 
"I like being a teacher": Career satisfaction, the work environment and work engagement

Hypothesis 1b: Because work burnout is strongly assocated with work engagement within the literature we suggest that career satisfaction will be significantly and negatively associated with each of the two dimensions of work burnout (exhaustion and disengagement).

Self Determination theory (Ryan and Deci, 2000) is compatible with JD-R (Bakker \& Demerouti, 2007) in that it predicts that favourable work environments will generate conditions of psychological safety in which people can thrive at work and experience high levels of work engagement (May et al., 2004). In view of consistent and robust findings supporting the validity of the JD-R (see Bakker and Demerouti), it is also anticipated that the JD-R theory will also predict work engagement and burnout in the current study. Furthermore, as previous research has found evidence for longitudinal influences of demands and resources in relation to work engagement (de Lange et al., 2008, Dollard and Bakker, 2010) it is anticipated that similar longitudinal associations will also be found in the current research. The following hypotheses will therefore each be tested with both cross-sectional and longitudinal data:

Hypothesis 2a: Psycho-social variables of control, reward, community, fairness, values, job satisfaction, career satisfaction, work-life balance and positive work-to-non-work spill-over will each have significant positive associations with the three engagement dimensions (vigour, dedication and absorption).

Hypothesis 2b: Psycho-social variables of control, reward, community, fairness, values, job satisfaction, career satisfaction, work-life balance and positive work-to-non-work spill-over will each have significant negative associations with the two burnout dimensions (exhaustion and disengagement) . 
"I like being a teacher": Career satisfaction, the work environment and work engagement

Hypothesis 3a: The three psycho-social variables of workload, work demands and negative work-to-non-work spill-over will each have significant negative associations with the three engagement dimensions (vigour, dedication and absorption).

Hypothesis 3b: The three psycho-social variables of workload, work demands and negative work-to-non-work spill-over will each have significant positive associations with the two burnout dimensions (exhaustion and disengagement).

\section{Method}

\section{Participants}

Respondents were 312 Australian teachers employed in Queensland, Australia who were members of the Queensland Independent Education Union (QIEU) and responded to two survey administrations investigating the influence of their psycho-social work environments upon levels of mental health. Respondents were selected by random draw of 2,800 names from the union membership data-base of 13,000 members. Surveys with reply-paid envelopes were sent to the home addresses of selected participants. On the first occasion 706 completed surveys were returned to researchers (response rate 25\%) and on the second occasion (six months later) 625 completed surveys were returned (response rate 23\%). Of these responses, 377 (53\%) could be matched as having completed both survey administrations. This research spanned a change of school year with Time one (T1) surveys distributed mid-semester two and Time two (T2) surveys distributed mid-semester one the following year. As union membership includes nonteaching members of schools' staff (such as teacher-aides and administrative personnel) the 
"I like being a teacher": Career satisfaction, the work environment and work engagement

current study is based on the $312(83 \%)$ responses from people who identified as being teaching members of staff.

Respondents included $n=90(29 \%)$ men and $n=222(71 \%)$ women. Mean age fell within the 45 to 49 year age group $(\mathrm{SD}=1.98)$. Twenty-four percent $(n=74)$ of respondents were under the age of 40 years and the majority $(57 \%, n=177)$ ranged in age from 45 to 59 years. This result is consistent with McKenzie et al. (2008) who reported the modal age of teachers within Australia as being 51 to 55 years. The majority of respondents worked full-time $(n=263,84 \%)$. Most respondents $(n=192,62 \%)$ had worked in their present position for less than 10 years. All respondents were university graduates with the majority having a Bachelor's degree $(n=248,80 \%)$ and 19\% $(n=60)$ a Master's degree. Most respondents were married $(79 \%, n=248)$ and nearly half of respondents reported they had no dependent children $(n=148$, $47 \%)$. Most respondents $(53.5 \%, n=167)$ were high school teachers, and 35\% $(n=108)$ taught in primary schools. Other schools represented included kindergartens and other early childhood learning centres. Respondents were asked to provide information of their hours of work (at school and at home) during the busiest week of semester and during a normal week of school. In regard to the busiest week of semester respondents reported a mean of 60.60 hours $(\mathrm{SD}=11.66)$ at $\mathrm{T} 1$ and 58.38 hours $(\mathrm{SD}=2.13)$ at $\mathrm{T} 2$. In more normal weeks of semester respondents reported working 45.63 hours $(\mathrm{SD}=12.48)$ at $\mathrm{T} 1$ and 46.15 hours $(\mathrm{SD}=13.42)$ at $\mathrm{T} 2$.

\section{Measures}

Areas of worklife survey (AWS); the six subscales from the AWS (Leiter and Maslach, 2006) were employed as measures of the psycho-social work environment. These six subscales are (1) workload, six-item measure (e.g., "I have enough time to do what's important in my job"; reverse scored item); (2) control, three-item measure (e.g., "I have control over how I do 
"I like being a teacher": Career satisfaction, the work environment and work engagement

my work"); (3) reward, four-item measure (e.g., "My work is appreciated"); (4) community, five-item measure (e.g., "I am a member of a supportive work group"); (5) fairness, six-item measure (e.g., "Management treats all employees fairly"); and (6) values, five-item measure (e.g., "My values and the organisation's are alike"). Responses to the AWS were coded on a five-point Likert scale from $1=$ "Strongly disagree" to 5 = "Strongly agree". High values therefore represent high values for each subscale. The current research found acceptable levels of scale reliability (Cronbach's Alphas) for the AWS subscales in the two phases of the survey: workload (T1 and T2 $\alpha=.81$ ), control (T1 $\alpha=.69$; T2 $\alpha=.72$ ), rewards (T1 $\alpha=.86 ; \mathrm{T} 2 \alpha=.85$ ), community (T1 $\alpha=.83$; T2 $\alpha=.81$ ), fairness (T1 $\alpha=.82 ; \mathrm{T} 2 \alpha=.81$ ), values (T1 $\alpha=.73$; T2 $\alpha=.77)$.

Oldenburg Burnout Inventory (OLBI). This measure of burnout was developed by Demerouti et al. (2002) and is considered to be comparable with the Maslach Burnout Inventory (Maslach et al., 1996) in terms of reliability and validity. Its two subscales were used as dependent variables in the current research. The subscales of the OLBI each contain eight-items: exhaustion (e.g., "I can tolerate the pressure of my work very well"); and disengagement (e.g., "This is the only type of work that I can imagine myself doing"). As the items are coded on a four-point scale from $1=$ "Strongly agree" to $4=$ "Strongly disagree", reverse scoring applies to negatively worded items. High scores therefore represent high levels of exhaustion and disengagement. The current research found acceptable levels of scale reliability (Cronbach's Alphas) for exhaustion (T1 $\alpha=.80 ; \mathrm{T} 2 \alpha=.81$ ) and disengagement (T1 $\alpha=.74$; T2 $\alpha=.76$ ). Utrecht Work Engagement Scale (UWES). Schaufeli and Bakker's (2003) short (nineitem) measure of work engagement was used as dependent variables in the current reseach. The instrument consists of three subscales with three items each: vigour (e.g., "At my work I feel 
"I like being a teacher": Career satisfaction, the work environment and work engagement

bursting with energy"); dedication (e.g., "I am proud of the work that I do"); and absorption (e.g., "I am immersed in my work"). The UWES is measured on a seven-point frequency response scale from $0=$ "Never" to $6=$ "Always". The current research found acceptable levels of scale reliability (Cronbach's Alphas) for vigour (T1 $\alpha=.82$; T2 $\alpha=.84)$; dedication (T1 $\alpha=$ $.81 ; \mathrm{T} 2 \alpha=.86)$; and absorption (T1 $\alpha=.74 ; \mathrm{T} 2 \alpha=.75)$.

Work Demands. We included five items from Siegrist et al.'s (2004) scale as an additional measure of the psycho-social work envrionment. The responses are coded as: $1=$ "does not apply"; 2 = "does apply, but it is not distressing"; 3 = "does apply and I am somewhat distressed"; 4 = "does apply and I am distressed" and 5 = "does apply and I am very distressed". Therefore high scores represent high levels of distress. The current study found acceptable levels of scale reliability (Cronbach's Alphas) for work demands: T1 $\alpha=.91$; T2 $\alpha=.90$.

Job satisfaction. Four items from Shaver and Lacey’s (2003) measure of job satisfaction were adapted for the current research. Shaver and Lacey's scale was created to measure the job satisfaction of nurses, consequently in the current research overt references to a medical context were changed to reflect the educational context of our sample. For example, the item stating "I am satisfied with the quality of time I am able to provide my patients" became "I am satisfied with the quality of time I am able to provide my students". The scale is measured with a fivepoint Likert scale from 1 = "Strongly disagree" to 5 = "Strongly agree". We found acceptable levels of scale reliability (Cronbach's Alphas) of $\alpha=.78$ for T1 and $\alpha=.81$ for T2. Although job satisfaction is often used as an outcome measure for research purposes (e.g., Brough and Pears, 2004), it was seen in the current research as a resource. This was because it records the respondent's thoughts on their immediate work environment, hence it was related to the JD-R in relation to the dependent variables. 
"I like being a teacher": Career satisfaction, the work environment and work engagement

Career satisfaction. Similar to job satisfaction, career satisfaction was adapted from Shaver and Lacey (2003) and was measured using the same Likert scale described for job satisfaction. The scale reported by Shaver and Lacey had three items, including "I like being a nurse", which became "I like being a teacher". However because an earlier qualitative project conducted by the current authors had found that some professionals also expressed a sense of incongruence between expectations held during their training days and the reality of their career (Author A, 2007) a fourth item was added to this measure: "The experience of being a teacher fulfils expectations I had when I was training for my career". The research produced acceptable levels of scale reliability (Cronbach's Alphas) for the resulting four-item career satisfaction measure: $\alpha=.83$ for T1 and T2. An additional item "Teachers attract a great deal of respect in the wider Australian community" (added for the same reason) was found to be incompatible with the other career satisfaction items.

Work-life Balance was assessed with a scale developed by Brough et al. (2009b) for the concise measurement of people's perception of balance between their work and non-work lives. The measure has four-items measured on a five-point Likert scale from 1= "Strongly Disagree" to $5=$ "Strongly Agree". A sample item is "I feel that the balance between my work and nonwork activities is currently about right". High scores indicate that the respondents perceive they have a high level of work-life balance. The current research found acceptable levels of scale reliability (Cronbach's Alphas) of T1 $\alpha=.93$ and T2 $\alpha=.92$.

Spill-over was measured with eight-items developed by Grzywacz and Marks (2000). This measure was included to gain a sense of the quality of balance experienced in relation to the interface between work and home. There are two sub-scales of four items, each measured on a five-point Likert scale from $1=$ "Strongly disagree" to $5=$ "Strongly agree". The first of these is 
"I like being a teacher": Career satisfaction, the work environment and work engagement

negative work-to-non-work spill-over (e.g., "Your job reduces the effort you can give to nonwork activities"). The second spill-over subscale is positive work-to-non-work spill-over (e.g., "The things you do at work make you a more interesting person at home and socially"). The current research found acceptable levels of scale reliability (Cronbach's Alphas) for both subscales respectively: $\alpha=.83$ (T1) and $\alpha=.86$ (T2), and $\alpha=.69$ (T1) and $\alpha=.76$ (T2). The work-family and family-work measures were included in the research as resources that could well support the JD-R model.

In addition, in both phases of the research respondents were asked to provide information as to the best and worst aspects of their job. The most common responses to these qualitative items in T1 were listed with checkboxes in T2. These were: colleagues, students, organisational communication, paperwork, hours, and pay. Respondents were asked to check all that applied to them in the best and worst categories.

\section{Results}

Table 1 provides the mean scores and standard deviations for the research variables for both sampling times. The majority of the variables did not differ significantly over time. Only two variables produced significantly differently means scores over time: control $t(311)=5.85, p$ $<.001$ and rewards $t(311)=-3.46, p<.001$. These results suggest that respondents perceived they had less control and greater rewards in their workplaces at T2. In regard to the single statement, "Teachers attract a great deal of respect in the wider Australian community"; achieved a mean score of $2.03(\mathrm{SD}=.93)$ at $\mathrm{T} 1$ and $2.07(\mathrm{SD}=.96)$ at $\mathrm{T} 2$. At $\mathrm{T} 18.7 \%(n=27)$ and at $\mathrm{T} 2$ $11 \%(n=34)$ of respondents agreed with this statement. The remainder of respondents were neutral (T1 \& T2 $n=43,13.8 \%$ ) or disagreed (T1 $n=242,77.6 \%$; T2 $n=235,75.3 \%$ ) with the 
"I like being a teacher": Career satisfaction, the work environment and work engagement

statement indicating a widespread perception among respondents that their profession was not highly regarded within the community.

Questionnaires were identical in both phases of the research. For the purposes of this research we have used T1 independent variables combined with T1 and T2 administrations of the dependent work engagement variables (absorption, dedication and vigor, Schaufeli and Bakker, 2003 ) in our longitudinal analyses. The purpose of this was to provide a test of endurance over time.

\section{-INSERT TABLE 1 AROUND HERE}

Table 2 provides correlations of study variables with Cronbach alpha coefficients appearing on the diagonal. It is interesting that workload did not demonstrate significant relationships with the engagement variables of vigour and dedication but had significant (positive) relationships with absorption, exhaustion and disengagement, demonstrating a lack of support for $\mathrm{H} 3 \mathrm{a}$, but resonating with $\mathrm{H} 3 \mathrm{~b}$ Workload also demonstrated significant positive associations with work demands and negative work-to-non-work spill-over (H2b). Work-life balance had strong negative associations with workload, work demands and negative work-tonon-work spill-over. While negative associations were produced between two of the three engagement dimensions (vigour and dedication) and workload, work demands and negative work-to-non-work spill-over, it is noted that the relationships are weak and, with the exception of absorption, mostly non-significant $(\mathrm{H} 2 \mathrm{~b})$. It is noteworthy that correlations between the three engagement variables (vigour, dedication and absorption) and the two burnout dimensions (exhaustion and disengagement) are at best moderate in size and, for absorption and exhaustion were all non-significant. 
"I like being a teacher": Career satisfaction, the work environment and work engagement

Hierarchical multiple regression analyses were conducted to test the research hypotheses both cross-sectionally and longitudinally. The cross-sectional regression equations were constructed as follows: at step 1 the control variables of gender, age group and employment status were entered. At step 2 career satisfaction was entered in order to have a separate assessment of the SDT and at step 3 the remaining workplace variables were enteredThe longitudinal regression equations were tested in the same way, but with $\mathrm{T} 2$ criterion variables. Each respective Time 1 criterion variable was therefore included in the analyses as a control at step 2; career satisfaction was entered at step 3 and the remaining variables at step 4.

Table 3 reveals that the strongest predictor variable within the cross-sectional equations was career satisfaction, thus supporting SDT perspectives, and that different patterns emerged in regard to the influence of different aspects of the work environment in the prediction of work engagement and burnout in support of JD-R perspectives. For example, negative work-to-nonwork spill-over was a strong predictor of both vigour and exhaustion, but not of the other criterion variables. Similarly, values (which measures congruence between individual and organisational values) was only significantly associated with dedication. An examination of $R^{2}$ change values demonstrated that with the exception of exhaustion (where $42 \%$ of the variance is explained by workplace variables), workplace variables explain a small amount of variance (1217\%). Community was the only workplace variable which did not demonstrate predictive capacity in regard to any of the criterion variables and for reasons of clarity, was removed from the analyses. Career satisfaction was significantly associated with all of the criterion variables and accounted for $27 \%$ of the variance in vigour, $36 \%$ of the variance in dedication, $12 \%$ of the variance in absorption, $10 \%$ of the variance in exhaustion and $32 \%$ of the variance in disengagement. Statistics for these regression equations were as follows: vigour, $F(15,296)=$ 
"I like being a teacher": Career satisfaction, the work environment and work engagement

$16.58, p<.001$; dedication $, F(15,296)=22.86, p<.001$; absorption $F(15,296)=7.69, p<$ .001 ; exhaustion, $F(15,296)=26.78, p<.001 ;$ and disengagement $F(15,296)=20.72, p<$ .001 .

\section{-INSERT TABLE 3 ABOUT HERE}

Results of the longitudinal regression analyses are provided in Table 4. The T1 criterion variable was the strongest predictor of $\mathrm{T} 2$ engagement and burnout variables accounting for at least $60 \%$ of the variance. The T1 career satisfaction predictor was significantly associated with $\mathrm{T} 2$ vigour, dedication and disengagement criterion variables demonstrating partial support for H1a and H1b. Specifically, a sense of satisfaction that they had chosen the right career endured and influenced people's vigour and dedication. Career satisfaction demonstrated a significant negative relationship with disengagement in the longitudinal analysis which indicates that people who are satisfied with their career are less likely to report that they are disengaged with their work. In comparison with the cross-sectional results, the workplace variables displayed different patterns of significance in the prediction of T2 engagement and burnout. Only positive work-to-non-work spill-over at T1 was significantly associated with dedication and was negatively associated with disengagement at T2. Statistics for these regression equations were as follows: vigour, $F(16,295)=20.56, p<.001$; dedication $, F(16,295)=18.72, p<.001$; absorption $F(16,295)=13.24, p<.001$; exhaustion, $F(16,295)=11.81, p<.001$; and disengagement $F(16,295)=13.10, p<.001$.

Finally, Figure 1 provides information as to respondents' perception of the best and worst features of their job environment. Most respondents marked more than one item in this section so percentages reflect the numbers of affirmative responses in each section (best or worst aspects of work). In regard to the best aspects of their job, the majority of respondents $(56 \%, n=175)$ 
"I like being a teacher": Career satisfaction, the work environment and work engagement

indicated colleagues, and $(74 \%, n=231)$ students. Seventeen percent $(n=53)$ checked pay, $9.3 \%(n=29)$ checked hours, $5.8 \%(n=18)$ checked organisational communication and $1 \%(\mathrm{n}=$ $3)$ indicated paperwork. Of the $38(12.2 \%)$ respondents who reported an "other" response for the best aspects of their job, aspects mentioned included intellectual challenge, holidays, community interaction and values.

Reference to negative aspects of work revealed a different pattern of responses. The majority of respondents $(64.1 \%, n=200)$ indicated that one of worst aspects of their job was paperwork, 38.5\% $(n=120)$ indicated hours, 36.5\% $(n=114)$ indicated organisational communication, 24\% $(n=75)$ indicated pay, 6.7\% $(n=21)$ indicated colleagues, and $4.5 \%(n=$ 14) indicated students. Aspects mentioned in relation to "other" with respect to the worst aspects of their job by the $11.1 \%(n=35)$ who marked this option, were school administration, difficult parents, having to take work home, curriculum issues and lack of respect for teachers in the community.

-INSERT FIGURE 1 ABOUT HERE-

\section{Discussion}

This research has found some persuasive evidence that supports compatibility between SDT and JD-R perspectives. The SDT association between fulfilment of psychological needs and work engagement (May et al., 2004) led to the current hypothesis that career satisfaction would demonstrate strong relationships with work engagement. In the current study, this was the most compelling finding, thus powerfully supporting the SDT perspective (Ryan and Deci, 2000) in regard to work engagement. Career satisfaction not only demonstrated strong relationships with all criterion variables in the current study, but also an enduring (over time) effect in regard 
"I like being a teacher": Career satisfaction, the work environment and work engagement

to vigour, dedication and disengagement. This suggests that people's aspirations and needs are reflected in their choice of career and how satisfied they are with that choice..

The current research demonstrates that while the JD-R (Bakker and Demerouti, 2007, Demerouti et al., 2001) accounts quite well for the exhaustion component of work burnout, its application to the work engagement construct is incomplete. This is interesting in view of the fact that the dedication component of work engagement as articulated by Schaufeli and Bakker (2003) does reflect an understanding that engaged workers find their work meaningful and fulfilling. Yet the JD-R model (devised by the same researchers) assumes an understanding that workers are motivated by an abundance of resources (Bakker and Demerouti, 2007, Demerouti et al. 2001). The current research finds that while the JD-R does have considerable utility in explaining exhaustion, lack of satisfaction in one's career provides a more adequate elucidation of disengagement. May et al.'s (2004) discussion of the role of the psycho-social work environment saw it as enabling the fulfilment of people's aspirations by providing an atmosphere in which they have a sense of psychological safety. This suggests a mediator (enabling rather than causative) role in the development of worker well-being for these variables. Therefore it is observed that personal satisfaction that one has chosen the right career provides a more enduring account of all facets of work engagement than do workplace variables used in the current research.

Nevertheless the JD-R has considerable explanatory power in accounting for burnout of workers based on experience of the immediate workplace environment. It is observed that the JD-R provided adequate explanations in the cross sectional analyses in that significant beta values were observed between the psycho-social predictor variables and their T1 criterions. Therefore it is suggested that a favourable balance of demands and resources may contribute to a 
"I like being a teacher": Career satisfaction, the work environment and work engagement

person's feeling of congruence in their work environment and hence their sense of well-being (Bakker and Demerouti, 2007). While conditions in the workplace may change over time, it is possible that people's response to a favourable experience is more enduring. Thus in the present research, T1 equivalent criterion variables accounted for most of the variance in $\mathrm{T} 2$ criterion variables. If this is the case it would be consistent with Rousseau's (1995, p.6) description of psychological contracts as "enduring mental models" which are not easily dislodged unless there was an overt breach of contract or other significant negative change within the organisation (see also Miller, 2001). However underlying people's day-to-day experiences in negotiating the challenges of their work is a sense of satisfaction or dissatisfaction with their choice of career (Shavey and Lacey, 2003). The current research has demonstrated that career satisfaction is an important associate of all aspects of work engagement. Hence it is suggested that a more comprehensive appreciation of work engagement is possible by combining the JD-R and the SDT perspectives.

One interesting finding in the current study is the lack of significance of community to all the criterion variables, in spite of the fact that teaching is by nature relationship-based and the respondents reported that students and colleagues were among the best aspects of their work. This finding could reflect Leiter and Maslach's (2006) framing of the community measure in terms of support, trust and cooperation specifically from work colleagues. According to Rice (2005) most of teachers' work is performed in classrooms away from the scrutiny of colleagues or superiors, hence teachers rarely work in traditional work-groups. Consequently, teachers' relationships with significant people in their work environment may fall outside the parameters of Leiter and Maslach's community measure. Rice (2005) maintained that the isolated autonomy experienced by teachers contributed to widespread insecurity in regard to perceived teaching 
"I like being a teacher": Career satisfaction, the work environment and work engagement

ability in relation to colleagues, assessment of societal judgements on the profession as a whole, and unrealistic expectations on the part of teachers themselves. Friedman's (2000) perception of teachers' sense of "unaccomplishment" also has salience to Rice's observation and points to a sense of insecurity in regard to people's intrinsic need for competency (Ryan and Deci, 2000).

Another interesting finding pertains to the nature of career satisfaction for teachers. The current finding of high career satisfaction juxtaposed with a prevailing perception that teaching has low community status has some accord with previous research. According to Dinham and Scott (2000), teachers in three countries (Australia, New Zealand and the UK) reported that their careers were intrinsically satisfying and extrinsically dissatisfying. Dinham and Scott suggested that this was because while teachers personally found their work meaningful and fulfilling, they perceived that it was not valued within the wider community. Thus fulfilment of people's psychological need to express authentic self-concepts (May et al., 2004) is undermined by a lack of fulfilment in regard to esteem needs (Bandura, 1969, Rosenstock et al., 1988) leading to dissonance and therefore insecurity. In addition, Timms and colleagues (2007) observed that teaching involves emotional labour where it is important to achieve a consistent level of functioning in daily interactions with children, which also creates a source of ambiguity (acting out emotions that are not felt can be a source of exhaustion).

This observation also provides some insight into the current findings with regards to work-to- non-work spill-over. Grzywacz and Marks (2000) suggested that skills, behaviours and values gained from a positive (or negative) experience at work might transfer their benefits across to the non-work interface, thus enriching (or being detrimental to) workers' lives. Greenhaus and Powell (2006) posited that positive work experiences enrich people's lives by providing skills (instrumental path) and psychological well-being (affective path) that promotes 
"I like being a teacher": Career satisfaction, the work environment and work engagement

positive relationships in multiple domains. The cross-sectional research of Grzywacz and Marks has been supported in the current longitudinal study with evidence that positive work-to-nonwork spill-over is associated with improved long-term mental health outcomes. While the current research's cross-sectional findings in regard to negative work to non-work spill-over (strongly associated with reduced vigour, more exhaustion and more disengagement) also support Grywacz and Mark's (2000) work, it is interesting that this relationship was not an enduring one.

\section{Contribution of the research}

The JD-R model is perhaps the most pervasive theoretical perspective used in research to explain both work engagement and burnout (e.g., Bakker and Demerouti, 2007, Demerouti et al., 2001, Xanthopoulou et al., 2007). Self-determination approaches are occasionally used in regard to worker health and well-being (e.g., Ryan and Deci, 2001, Ryan and Deci, 2000) with some general theoretical applications to work engagement (see, May et al., 2004, Saks, 2006). However previous work has not specifically linked career satisfaction (Shaver and Lacey, 2003) with either work engagement or burnout. The current research suggests that while psycho-social factors (such as the resources/demands model) may provide some explanation of work engagement, other more intrinsic factors may well be involved in energising and absorbing people at work (see, May et al., 2004). In the case of teachers the association has previously been made between expectations of professional excellence and burnout (e.g., Friedman, 2000) but not work engagement. While the current study has supported JD-R predictions of profound psycho-social influences in regard to teacher well-being at work, it has demonstrated that one of the most important predictors is a sense of having chosen a career that is personally meaningful and fulfilling.

\section{Research limitations}


"I like being a teacher": Career satisfaction, the work environment and work engagement

While the current study provides longitudinal analyses that potentially assist in highlighting a causal framework for the criterion variables, the low response rate produced by this research is a potential research limitation. Both administrations of the survey took place near the middle of the respective semesters. In terms of intense activity, the middle of semester is usually not as busy as the end of semester for teachers; however it is possible that the appearance of the survey was viewed by the teaching respondents as an added imposition on an already heavy workload, which may explain the low response rate. Krosnick (1999) observed that people who work long hours are less likely to respond to surveys. Therefore, given that respondents in the present research reported long working hours in normal, as well as in busy weeks, this may explain the low response rate. It is also noted that the present research found that the age and gender of respondents were equivalent to those previously found by Australian Government who reported statistics relating to the Australian population of teachers (McKenzie et al., 2008), suggesting that the respondents in the current research are generally representative of the Australian teaching population.

\section{Theoretical Implications}

Because employee mental health is such an important aspect of organisational functioning (ILO, 2000, Bakker and Demerouti, 2007, Maslach and Leiter, 1997, Schaufeli, 2004) it is important to understand the factors that both contribute to and undermine it. It is observed that much of the recent research involving work engagement has been derived from previous research involving work burnout and it has been assumed that engagement has similar predictors (Maslach et al., 2001). This has led to models predicting work engagement such as the JD-R (Bakker and Demerouti, 2007) which have assumed that engagement and burnout have the same antecedents (e.g. Maslach et al., 2001). Dollard and Bakker's (2010) recent research has 
"I like being a teacher": Career satisfaction, the work environment and work engagement

expanded the JD-R to incorporate the organisational psychosocial safety climate, which is seen as the setting in which the balance or imbalance of demands and resources impacts on employees. However, Dollard and Bakker (2010) did not consider SDT perspectives such as an individual's motivation to achieve their potential which is of necessity at the core of finding work meaningful and fulfilling (Ryan and Deci, 2000, Ryan and Deci, 2001). Similarities are noted between the PSC (Dollard and Bakker) and May et al.'s (2004) concept of psychological safety. There appears to be little doubt that such a work environment is consistent with the facilitation of work engagement. We suggest that this may be the meeting point of SDT and JDR theory. One theoretical perspective (SDT) suggests that fulfilling human psychological needs is a precursor to engagement with work (May et al., 2004, Ryan and Deci, 2000, Saks, 2006). The other perspective (JD-R) appears to have derived appreciation of work engagement and worked backwards, firstly from work burnout and its psycho-social predictors (Bakker and Demerouti, 2007), currently focussing on the environment in which people respond to the balance of demands and resources (Dollard and Bakker). Consequently it is observed that the theories of SDT and JD-R while coming from different directions appear to be compatible, with each perspective enriching the other.

Career satisfaction is closely aligned with people's choice of career and their satisfaction with how that choice has evolved over their working experience (Shaver and Lacey, 2003). While job satisfaction (which is more organisation focused) is widely used in organisational research (e.g., Brough and Frame, 2004), career satisfaction has not been widely tested to date. The career variable used in the current research actually names the respondent's career and asks whether they like it, whether they feel efficacious within the career and whether it fulfils their expectations. It is therefore proposed that this measure of career satisfaction is more closely 
"I like being a teacher": Career satisfaction, the work environment and work engagement

linked to a sense of realisation of aspirations. The fact that this variable was significantly associated with vigour, dedication, absorption and disengagement over time provides an extra dimension to understanding workers' mental health; in that it suggests that the choice of career is influential in employees' experiences of work engagement.

\section{Practical Implications}

The current research found that teachers are generally highly satisfied with their choice of career and that this choice is significantly associated with their experiences of work engagement. The literature suggests that engaged workers are more productive (Schaufeli, 2004) and are more likely to cooperate voluntarily in regard to their work (Saks, 2006). However, the teachers in the present research also indicated that they did not believe their profession was highly regarded in the wider community. Fink (2003) observed that teachers reduced their participation in extracurricular activities (such as school sports and drama) because of increases in work demands and a sense that their work was not valued. It is observed that bright students would be very aware of this incongruence and consequently may not consider teaching as a choice of profession for themselves. In view of the fact that teaching is an ageing profession (McKenzie et al., 2008) it is necessary that this perception of the profession be addressed and that teachers be enabled to feel efficacious about their work (Bandura, 1969; Friedman, 2000) in order to improve the teaching career profile among potential teachers.

\section{Conclusion}

The current research found support for a combination of two theoretical perspectives in regard to explaining teachers' mental health. The SDT (Ryan and Deci, 2000) which linked the fulfilment of psychological needs to work engagement provided an important framework for understanding teachers' work engagement. However we did find evidence that the psycho-social work 
"I like being a teacher": Career satisfaction, the work environment and work engagement

environment also has an important role in engagement and burnout. While this provides support for the JD-R model (Bakker and Demerouti, 2007) it also endorses May et al.'s (2004, SDT) vision of psycho-social factors of the work environment contributing to a sense of psychological safety, thus enabling psychological need fulfilment (Ryan and Deci, 2000). We found that teachers' career satisfaction has a powerful influence on their long term engagement or disengagement with their work. The contribution of favourable work environments is also important in establishing a baseline of employee mental health which is enduring over time. In view of the fact that teaching is a profession that is vulnerable to attrition (via impending large scale retirements; McKenzie et al., 2008) it is suggested that factors impinging on career satisfaction and recruitment of new teachers are addressed.References

BAKKER, A. B. \& DEMEROUTI, E. 2007. The job demands-resources model: State of the art. Journal of Managerial Psychology, 22, 309-328.

BAKKER, A. B., HAKANEN, J. J., DEMEROUTI, E. \& XANTHOPOULOU, D. 2007. Job resources boost work engagement particularly when job demands are high. Journal of Educational Psychology, 99, 274-284.

BANDURA, A. 1969. Social-learning theory of indentifactory processes. In: GOSLIN, D. A. (ed.) Handbook of Socialization Theory and Research Rand McNally

BEARD, K. \& HOY, W. 2010. The nature, meaning, and measure of teacher flow in elementary schools: A test of rival hypotheses. Educational Administration Quarterly, 46, 426-458

BROUGH, P. \& FRAME, R. 2004. Predicting police job satisfaction and turnover intentions: The role of social support and police organisational variables. New Zealand Journal of Psychology, 33, 8-16.

BROUGH, P., O’DRISCOLL, M., KALLIATH, T., COOPER, C. L. \& POELMANS, S. 2009a. Workplace psychological health: Current research and practice, Cheltenham, U.K, Edward Elgar.

BROUGH, P. \& PEARS, J. 2004. Evaluating the influence of the type of social support on job satisfaction and work related psychological well-being. International Journal of Organisational Behaviour, 8, 472-485. 
"I like being a teacher": Career satisfaction, the work environment and work engagement

BROUGH, P., TIMMS, C. \& BAULD, R. 2009b. Measuring work-life balance: Validation of a new measure across five Anglo and Asian samples. Eighth Industrial and Organisational Psychology Conference. Sydney, Australia: Australian Psychological Society.

CSIKSZENTMIHALYI, M. 1990. Flow: The psychology of optimal experience, New York, Harper and Row.

DE LANGE, A., DE WITTE, H. \& NOTELAERS, G. 2008. Should I stay or should I go? Examining longitudinal relations among job resources and work engagement for stayers versus movers. Work \& Stress, 22, 201-223.

DEMEROUTI, E., BAKKER, A., VARDAKOU, I. \& KANTAS, A. 2002. The convergent validity of two burnout instruments: A multitrait-multimethod analysis. European Journal of Psychological Assessment, 19, 12-23.

DEMEROUTI, E., BAKKER, A. B., NACHREINER, F. \& SCHAUEFELI, W. B. 2001. The job demands-resources model of burnout. Journal of Applied Psychology, 86, 499-512.

DINHAM, S. \& SCOTT, C. 2000. Moving into the third, outer domain of teacher satisfaction. Journal of Educational Administration, 38, 379-396.

DOLLARD, M. \& BAKKER, A. 2010. Psychosocial safety climate as a precursor to conducive work environments, psychological health problems and employee engagement. Journal of Occupational \& Organisational Psychology, 83, 579-599.

EASTHOPE, C. \& EASTHOPE, G. 2000. Intensification, extension and complexity of teachers' workload. British Journal of Sociology of Education, 21, 43-58.

FINK, D. 2003. The law of unintended consequences: The 'real' cost of top-down reform. Journal of Educational Change, 4, 105-128.

FRIEDMAN, I. A. 2000. Burnout in teachers: Shattered dreams of impeccable professional performance. Journal of Clinical Psychology, 56, 595-606.

GARDNER, C. \& WILLIAMSON, J. 2006. Having a life outside teaching: The nature and amount of teachers' out-of-hours work. Australian Teacher Education Association Conference. Melbourne, Australia.

GILL, F. 1999. The meaning of work: Lessons from sociology, psychology, and political theory. The Journal of socio-Economics, 28, 725-743.

GREENHAUS, J. H. \& POWELL, G. N. 2006. When work and family are allies: A theory of work-family enrichment. Academy of Management Review, 31, 72-92. 
"I like being a teacher": Career satisfaction, the work environment and work engagement

GRZYWACZ, J. G. \& MARKS, N. F. 2000. Reconceptualizing the work-family interface: An ecological perspective on the correlates of positive and negative spill-over between work and family. Journal of Occupational Health Psychology, 5, 111-126.

HARGREAVES, A. \& FINK, D. 2004. The Seven principles of sustainable leadership. Educational Leadership, 61, 8-13.

HOWARD, S. \& JOHNSON, B. 2004. Resilient teachers: resisting stress and burnout. Social Psychology of Education, 7, 399-430.

ILO 2000. Mental Health in the Workplace: Introduction and Executive Summaries. Geneva: International Labor Organisation.

KIM, W. C. \& MAUBORGNE, R. 2005. Blue Ocean Strategy: How to Create Uncontested Market Space and Make the Competition Irrelevant, Boston, Massachusetts Harvard Business School Publishing

KROSNICK, J. A. 1999. Survey research. Annual Review of Psychology, 50, 537-567.

LEITER, M. \& MASLACH, C. 2006. The areas of worklife survey manual, Wolfville, NS, Center for Organizational Research and Development.

MASLACH, C., JACKSON, S. E., LEITER, M. P. \& SCHAUEFELI, W. B. 1996. Maslach Burnout Inventory, Palo Alto, Consulting Psychologists Press.

MASLACH, C. \& LEITER, M. P. 1997. The truth about burnout: How organizations cause personal stress and what to do about it.Jossey-Bass, San Francisco, CA Jossey-Bass.

MASLACH, C. \& LEITER, M. P. 2008. Early predictors of job burnout and engagement. Journal of Applied Psychology, 93, 498-512.

MASLACH, C., SCHAUEFELI, W. B. \& LEITER, M. P. 2001. Job burnout. Annual Review of Psychology, 52, 397-422.

MAY, D. R., GILSON, R. L. \& HARTER, L. M. 2004. The psychological conditions of meaningfulness, safety and availability and the engagement of the human spirit at work. American Psychologist, 55, 68-78.

MCKENZIE, P., KOS, J., WALKER, M. \& HONG, J. 2008. Staff in Australia's Schools 2007. Canberra: Department of Education, Employment and Workplace Relations.

MILLER, D. T. 2001. Disrespect and the experience of injustice. Annual Review of Psychology, $52,527-553$. 
"I like being a teacher": Career satisfaction, the work environment and work engagement

O'DRISCOLL, M., BROUGH, P., TIMMS, C. \& SAWANG, S. 2010. Engagement with Information and communication technology and psychological well-being. In: PERREWÉ, P. L. \& GANSTER, D. C. (eds.) New Developments in Theoretical and Conceptual Approaches to Job Stress, Research in Occupational Stress and Well Being. Emerald Group Publishing.

RICE, S. 2005. "You don't bring me flowers anymore": A fres look at the vexed issue of teacher status. Australian Journal of Education, 49, 182-196.

ROSENSTOCK, I. M., STRECHER, V. J. \& BECKER, M. H. 1988. Social learning theory and the health belief model. Health Education Quarterly, 15, 175-183.

ROTHBARD, N. P. 2001. Enriching or depleting? The dynamics of engagement in work and family roles. Administrative Science Quarterly, 46, 655-684.

ROUSSEAU, D. M. 1995. Psychological contracts in organizations: Understanding written and unwritten agreements, Thousand Oaks, CA, Sage.

RYAN, R. M. \& DECI, E. L. 2000. Self-determination theory and the facilitation of intrinsic motivation, social development and well-being. American Psychologist, 55, 68-78.

RYAN, R. M. \& DECI, E. L. 2001. On happiness and human potentials: A review of research on hedonic and eudaimonic well-being. Annual Review of Psychology, 52, 139-170.

RYAN, R. M., HUTA, V. \& DECI, E. L. 2008. Living well: A self-determination theory perspective on eudemonia. Journal of Happiness Studies, 9, 139-170.

SAKS, A. M. 2006. Antecedents and consequences of employee engagement. Journal of Managerial Psychology, 21, 600-619.

SCHAUFELI, W. B. 2004. The future of occupational health psychology. Applied Psychology: An International Review, 53, 502-517.

SCHAUFELI, W. B. \& BAKKER, A. B. 2003. Utrecht Work Engagement Scale: Preliminary Manual, Utrecht, Occupational Health Psychology Unit, Utrecht University.

SCHAUFELI, W. B., TARIS, T. \& VAN RHENEN, W. 2008. Workaholism, burnout and work engagement: Three of a kind or three different kinds of employee well being? Applied Psychology: An International Review, 57, 173-203.

SHAVER, K. H. \& LACEY, L. M. 2003. Job and career satisfaction among staff nurses: Effects of job setting and environment. The Journal of Nursing Administration, 33, 166-172. 
"I like being a teacher": Career satisfaction, the work environment and work engagement

SIEGRIST, J., STARKE, D., CHANDOLA, T., GODIN, I., MARMOT, M., NIEDHAMMER, I. \& PETER, R. 2004. The measurement of effort-reward imbalance at work: European comparisons. Social Science and Medicine, 58, 1483-1499.

SONNENTAG, S. \& BAYER, U.-V. 2005. Switching off mentally: Predictors and consequences of psychological detachment from work during off-job time. Journal of Occupational Health Psychology, 10, 393-414.

TIMMS, C., BROUGH, P. \& GRAHAM, D. 2012. Burnt-out but engaged: The co-existence of psychological burnout and engagement Journal of Educational Administration, 50.

TIMMS, C., GRAHAM, D. \& COTTRELL, D. 2007. 'I just want to teach': Queensland independent teachers and their workload. Journal of Educational Administration, 45, 569-586.

TIMMS, C., LANKSHEAR, C., ANDERSON, N. \& COURTNEY, L. 2008. Riding a hydra: Women ICT professionals' perceptions of working in the Australian ICT industry. Information Technology and People, 21, 156-177.

WILLIAMSON, J. \& MYHILL, M. 2008. Under 'constant bombardment': Work intensification and the teachers' role. In: JOHNSON, D. \& MACLEAN, R. (eds.) Teaching: Professionalization, Development and Leadership. Springer Science.

XANTHOPOULOU, D., BAKKER, A. B., DEMEROUTI, E. \& SCHAUFELI, W. B. 2007. The role of personal resources in the job demands-resources model, International Journal of Stress Management Vol 14(2) May 2007, 121-141. 